ORIGINAL ARTICLE

\title{
Work related shoulder disorders: quantitative exposure- response relations with reference to arm posture
}

\author{
S W Svendsen, J P Bonde, S E Mathiassen, K Stengaard-Pedersen, L H Frich
}

Occup Environ Med 2004;61:844-853. doi: 10.1136/oem.2003.010637

See end of article for authors' affiliations ....................

Correspondence to: Dr S W Svendsen, Department of Occupational Medicine Aarhus University Hospital, Noerrebrogade 44, Building 02C, DK-8000 Aarhus C, Denmark: swsve@akh.aaa.dk

Accepted 24 March 2004

\begin{abstract}
Aims: To determine quantitative exposure-response relations between work with highly elevated arms and supraspinatus tendinitis, shoulder pain with disability, and shoulder pain without disability.

Methods: A cross sectional study was conducted in a historical cohort of 1886 males from three occupational groups. Exposure measurements were performed for four consecutive working days in a random sample of 72 currently employed subjects. Individual work histories were obtained by questionnaire and register data. Health status was ascertained by physical examination blinded towards exposure and symptoms. Data were analysed by generalised estimating equation and multiple logistic regression with adjustment for potential confounders.

Results: For current upper arm elevation above $90^{\circ}$, a duration increment of $1 \%$ of the daily working hours was associated with odds ratios of $1.23(95 \% \mathrm{Cl} 1.10$ to 1.39$)$ for supraspinatus tendinitis, $1.16(95 \% \mathrm{Cl}$ 1.08 to 1.24$)$ for shoulder pain with disability, and $1.08(95 \% \mathrm{Cl} 1.04$ to 1.13$)$ for shoulder pain without disability. The outcomes were not related to duration of employment in one of the three trades.

Conclusions: Quantitative exposure-response relations were established between current work with highly elevated arms and clinically verified shoulder disorders. Substantial long term cumulative effects were not shown. A potential for primary prevention was revealed.
\end{abstract}

$\mathrm{S}$ houlder disorders have considerable impact on sickness absence, ${ }^{1}$ utilisation of primary ${ }^{2}$ and secondary ${ }^{3}{ }^{4}$ health services, and premature withdrawal from the labour market. ${ }^{5}$ Several occupational exposures have been associated with shoulder complaints and disorders; these include work with elevated arms, monotonous repetitive work, and forceful exertions. ${ }^{67}$ However, most epidemiological investigations into the work relatedness of shoulder disorders suffer from methodological limitations, in particular concerning exposure assessment and verification of disorders. ${ }^{8}$ The present lack of knowledge hampers the development of guidelines and regulations to prevent work related shoulder disorders. ${ }^{9}$

Work with elevated arms has been hypothesised to cause degenerative changes in the rotator cuff tendons ${ }^{10}$ and thus predispose to tears. It is unclear how high the arms must be elevated and for how long a time before the harmful effects occur. Existing evidence points to elevation angles above $60^{\circ}$, but the majority of studies cannot separate effects of postural load and monotonous repetitive work. ${ }^{6}$ Few studies have focused on elevation angles above $90^{\circ},,^{11-13}$ and the literature is scarce on the effects of varied patterns of arm elevation. ${ }^{14-16}$ We aimed to establish quantitative exposure-response relations between work with highly elevated arms and shoulder disorders. The study was based on direct measurements of upper arm elevation, register based data on occupational histories, and physical examinations blinded to exposure and symptoms.

\section{METHODS}

\section{Population}

We conducted a cross sectional study in a historical cohort of male machinists, car mechanics, and house painters. Within a defined geographical area, 646 companies were identified in the Danish Central Business Register (www.cvr.dk) by the end of April 1999. We selected 258 index companies according to criteria on company size, location, and work tasks. ${ }^{16 a}$ The final company base comprised 29 machine shops, 110 garages for domestic cars, and 119 painters' workshops. Companies with less than five journeymen were excluded, and machine shops were only included if they had computer operated numerically controlled tools. Additionally, we ensured that the relatively few machine shops were evenly distributed in the study district. By linkage with the Register of the Danish Labour Market Supplementary Pension Scheme (www.atp.dk) we identified 15414 male employees who had worked in an index company at least one year after the age of 30 during a 10 year period (1989-98), with an employment level not less than $50 \%$ in the year concerned. Figure 1 displays further steps in the establishment of the study population. Criteria on residence (in Jutland or Funen) and age ( $<65$ years) had to be fulfilled, and we excluded men without the training of apprentices in one of the three trades. The last mentioned information was primarily obtained from the index companies where personnel from wage administrations or shop stewards checked full lists of names. A limited number turned out not to be journeymen according to a questionnaire (mailed to a total of 3421 men), or telephone interviews with non-respondents. This left 2945 men including 593 whose occupation was not determined. Questionnaire data were delivered by 2053. Thus, the questionnaire was completed by at least 70\% (2053/ 2945) of the relevant tradesmen, varying from $67 \%$ among house painters to $70 \%$ among machinists, and $73 \%$ among car mechanics.

We excluded questionnaire respondents who had worked less than one year as a journeyman in one of the three trades or more than three years in other jobs with considerable mechanical shoulder exposure in terms of awkward postures, force requirements, and highly repetitive work. To identify such exposed jobs, job titles from individual occupational histories (see below) were independently judged by two

Abbreviations: $\mathrm{Cl}$, confidence interval; $\mathrm{OR}$, odds ratio; $\mathrm{r}^{2}$, squared Pearson correlation coefficient 
Main messages

- Quantitative exposure-response relations were established between current duration of work with highly elevated arms and clinically verified supraspinatus tendinitis, shoulder pain with disability, and shoulder pain without disability.

- Substantial cumulative effects of prolonged exposure were not shown.

observers (JPB and SWS), and the few discrepancies between the observers were settled by consensus.

Questionnaire data were used to select subjects for physical examination. Subjects were screening positive for the dominant or non-dominant shoulder if they had been at least moderately troubled by shoulder pain or discomfort during the previous 12 months. Side specific exclusion criteria were non-participation in the physical examination although the subject was screening positive for the shoulder in question, and shoulder disorders of non-occupational origin (fig 1). Among the subjects who were screening positive for one or both shoulders, the percentage who attended the physical examination was $90 \%$ among machinists $(n=111)$, and $83 \%$ among car mechanics $(n=135)$ and house painters $(\mathrm{n}=266)$.

The total study population consisted of 1886 present or former journeymen in one of the three trades, viz 1752 for the dominant and 1797 for the non-dominant shoulder. The currently employed subpopulation comprised the 1627 members of the total study population who were actively employed in or outside the three trades, excluding individuals who were self employed or who had left their trade because of shoulder pain. Table 1 shows the characteristics of the participants. The project was approved by the scientific ethical committee system.

\section{Exposure assessment}

An exposure survey was conducted from August 1999 to February 2000. ${ }^{16 a}$ At the beginning of this period, the index companies employed altogether 942 machinists, 692 car mechanics, and 1579 house painters (men and women, all age groups). From each occupational group 13 pairs of colleagues were sampled at random. Paired sampling was motivated by logistic concerns. For each subject, one working week was selected for data collection. All three occupational groups were represented throughout the data collection in order to cover seasonal variability. Inclusion criteria for the exposure survey were at least one year of employment as a journeyman, male sex, age 30-65 years, and at least four scheduled working days in the specified week. Subjects were excluded if they had shoulder complaints that interfered with their performance at work. When a subject was excluded $(n=1)$ or did not want to participate $(n=6)$, he was replaced by another randomly sampled subject, preferably from the same company.

Whole-day measurements of upper arm elevation were obtained for four consecutive working days of 26 machinists, 23 car mechanics, and 23 house painters. A total of 41 participants in the exposure survey were also members of the currently employed subpopulation, whereas the remainder were not, most often because they did not answer the questionnaire. Upper arm elevation was measured with respect to gravity in six $15^{\circ}$ intervals from $0^{\circ}$ to $90^{\circ}$, and one interval covering angles larger than $90^{\circ}$. The measurements were performed with a frequency of $1 \mathrm{~Hz}$ using an inclinometer (abduflex) which consisted of a sensor on each
Policy implications

- The study can contribute to the development of effective guidelines for prevention of work related shoulder disorders.

upper arm connected to a data logger in the belt. ${ }^{17}$ The capacity of the loggers allowed continuous registration for eight hours. In a few cases of longer working hours, recordings for the first hours were saved and the equipment restarted.

The data were processed to give the percentage of daily working hours spent with the right or left upper arm elevated more than $90^{\circ}$, more than $60^{\circ}$, and more than $30^{\circ}$. Exposure variation analysis was performed to give the time proportion of uninterrupted arm elevation above $90^{\circ}$ for sequences of at least 5, 10, and 20 seconds. ${ }^{18}$ Combined posture and force requirements were assessed by a torque index for the glenohumeral joint. The index was based on force scores assigned to work tasks by experienced tradespeople combined with the measured elevation angles. Average job exposures were assessed by calculating the arithmetic mean across four days for each subject, and subsequently, averaging these individual specific mean exposures for each occupation. Figure 2 and table 2 provide information on the mechanical exposures according to the exposure survey.

Occupational histories were extracted from the Register of the Danish Labour Market Supplementary Pension Scheme (www.atp.dk) which contains person identifiable year-byyear information on employment for all wage earners in Denmark since 1 April 1964. The registered employment level accounts for overtime and short time work. We enclosed a person specific register based list of previous jobs in each questionnaire. Job titles were obtained for approximately $95 \%$ of the registered working years, of which $10-15 \%$ fell outside the three trades.

We assigned two exposure estimates to each shoulder based on the average job exposures from table 2 (for each shoulder and each trade) and individual occupational histories. For house painters who used both hands equally well, we used the mean of the measured average job exposures for both shoulders. Within the three trades, reduction factors were assigned to jobs with special work functions (for example, 0.25 to a car mechanic's job as a foreman), and extraneous jobs were assessed as unexposed. Current upper arm elevation above $90^{\circ}$ was expressed as the percentage of daily working hours spent with the arm elevated more than $90^{\circ}$ obtained by time weighted averaging of exposures for jobs held during the previous 10 months. Lifetime upper arm elevation above $90^{\circ}$ was assessed by first calculating the product of the exposure for each job in the occupational history, the reduction factor (if any), and the duration of employment (months), and then summarising across all jobs. Thus, lifetime upper arm elevation was expressed as the total number of full time working months spent with the arm elevated more than $90^{\circ}$. Duration of employment in one of the three trades was used as a third exposure estimate. Table 1 presents exposure data for the total study population and for the currently employed subpopulation.

Psychosocial working conditions were assessed by 20 items selected from the medium sized version of the Copenhagen Psychosocial Questionnaire. ${ }^{19}$ We grouped the items into three scales assessing job demands (quantitative, cognitive, and sensorial), job control (influence at work, degrees of freedom), and social support. Each scale ranged from 0 to 
See text

Danish Civil Registration System

Index company, questionnaire, telephone interview ${ }^{\star}$

Questionnaire

Questionnaire

Expert judgement

Questionnaire, physical examination

Questionnaire

Physical examination

\section{TOTAL STUDY POPULATION}

Questionnaire

CURRENTLY EMPLOYED

SUBPOPULATION
- Dead

- Address inaccessible

- Residence outside Jutland and Funen

- Age $>65$ by 30 March 2000

- Not a journeyman in relevant trades

- No questionnaire response

- Duration of employment as a journeyman $<1$ year

- Employment in other jobs with considerable mechanical shoulder load $>3$ years

No participation in physical examination although screening positive ${ }^{\ddagger}$ (side specific exclusion)

- Previous injury to the shoulder ${ }^{\S}$ (side specific exclusion)

- Shoulder surgery before the age of 18 (side specific exclusion)

- Systemic disease

- Radiating pain provoked by test movements of the neck $(n=4)$

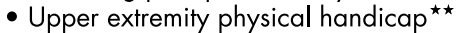

- Anterior instability (side specific exclusion) ( $n=2)$

- Adhesive capsulitis (side specific exclusion) $(n=1)$

Present and former machinists, car mechanics, and house painters $\longrightarrow$

- Self employed

- Out of active employment

- Left trade because of shoulder pain

Currently employed in or outside the three trades

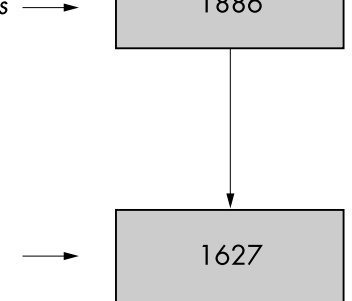

Figure 1 Establishment of study population starting from a historical cohort extracted from the Register of the Danish Labour Market Supplementary Pension Scheme. All subjects were male. *A total of 376 questionnaire non-respondents were briefly interviewed by telephone (this number differs from the number stated in the discussion $(n=278)$ which was the number of interviewed non-respondents who turned out to be eligible). tIncluding 593 subjects whose occupation was not determined. ¥Subjects were screening positive if they had been at least moderately troubled by shoulder pain or discomfort during the previous 12 months. §Fracture of the clavicula, humerus, or scapula, dislocation of the acromioclavicular or humeroscapular joint. 'Cancer with general debility $(n=2)$, myasthenia gravis, ankylosing spondylitis, rheumatoid arthritis, Wegener's granulomatosis, acromegaly. ${ }^{*}$ Sequelae after poliomyelitis $(n=2)$, atrophic upper limb after trauma, bilateral surgery for acromioclavicular arthrosis.

100. For each individual, job demands were classified as high if the score was larger than 70; job control and social support were classified as low if the scores were less than 50.

\section{Outcome assessment}

All screening positive subjects $(n=606$ in the total study population) were invited to a physical examination, as was a random sample of 300 screening negative subjects, 100 from each occupational group. The following screening questions were used for the right and left shoulder, respectively:
- Have you at any time during the last 12 months had pain or discomfort in your right (left) shoulder? (no/yes) ${ }^{20}$

- How much have you been troubled by pain or discomfort in your right (left) shoulder during the last 12 months? (a little bit, somewhat, quite a bit, much, very much)

The second question was to be answered only if the first question was answered by "yes". Next to the questions a small pre-shaded illustration helped to define the area of interest. Screening positiveness required an answer of at least "somewhat". 
Table 1 Personal and occupational characteristics of participants $(n=1886)$; factors specific to person and shoulder (all subjects were male)

\begin{tabular}{|c|c|c|c|c|c|c|}
\hline & $\begin{array}{l}\text { Machinis } \\
n=529\end{array}$ & & $\begin{array}{l}\text { Car mec } \\
\mathrm{n}=599\end{array}$ & & $\begin{array}{l}\text { House } \\
n=75\end{array}$ & \\
\hline Person specific factors & & & & & & \\
\hline $\begin{array}{l}\text { Age (years), mean } \\
\text { (SD) }\end{array}$ & $\begin{array}{l}46.3 \\
(9.8)\end{array}$ & & $\begin{array}{l}45.0 \\
(8.4)\end{array}$ & & $\begin{array}{l}48.4 \\
(9.2)\end{array}$ & \\
\hline Height & & & & & & \\
\hline$>185 \mathrm{~cm}(\%)$ & 18.0 & & 15.5 & & 12.7 & \\
\hline Body mass index & & & & & & \\
\hline$\geqslant 30 \mathrm{~kg} / \mathrm{m}^{2}(\%)$ & 11.3 & & 7.0 & & 9.9 & \\
\hline Handedness & & & & & & \\
\hline Left handed (\%) & 4.7 & & 7.4 & & 10.2 & \\
\hline Both handed (\%) & 4.0 & & 5.3 & & 5.2 & \\
\hline Current smokers (\%) & 38.1 & & 31.0 & & 45.0 & \\
\hline Never smokers (\%) & 37.6 & & 44.7 & & 24.5 & \\
\hline Pack-years of smoking* & & & & & & \\
\hline$<20+(\%)$ & 35.0 & & 36.4 & & 38.1 & \\
\hline$\geqslant 20(\%)$ & 27.4 & & 18.9 & & 37.3 & \\
\hline Shoulder intensive sports $\ddagger$ past 10 months & & & & & & \\
\hline $\begin{array}{l}>0 \mathrm{~h} / \text { week (\%) } \\
\text { Shoulder intensive sports } \neq \text {, total number }\end{array}$ & 27.0 & & 29.7 & & 21.4 & \\
\hline$>1600 \mathrm{~h}(\%)$ & 30.1 & & 21.7 & & 19.6 & \\
\hline Predisposing disorders§ (\%) & 7.2 & & 10.0 & & 10.7 & \\
\hline Current occupation & & & & & & \\
\hline Employee in trade (\%) & 80.3 & & 76.0 & & 75.3 & \\
\hline Employer in trade (\%) & 0.2 & & 1.7 & & 5.2 & \\
\hline Other occupation (\%) & 7.9 & & 15.9 & & 5.8 & \\
\hline Out of active employment (\%) & 11.5 & & 6.5 & & 13.7 & \\
\hline $\begin{array}{l}\text { Duration of employment in trade (years), mean } \\
\text { (SD) }\end{array}$ & $\begin{array}{l}21.7 \\
(8.8)\end{array}$ & & $\begin{array}{l}20.8 \\
(8.8)\end{array}$ & & $\begin{array}{l}22.0 \\
(8.5)\end{array}$ & \\
\hline Psychosocial working conditions ${ }^{* \star}$, t† & & & & & & \\
\hline High job demands (\%) & 32.3 & & 28.1 & & 19.9 & \\
\hline Low job control (\%) & 38.0 & & 37.1 & & 23.8 & \\
\hline Low social support (\%) & 33.6 & & 33.8 & & 44.0 & \\
\hline Shoulder specific factors & D & ND & D & ND & D & ND \\
\hline Shoulder surgery after the age of 17 (\%) & 1.0 & 0.4 & 0.7 & 0.2 & 1.2 & 0.7 \\
\hline Changes in work practices due to shoulder pain (\%) & 2.6 & 2.3 & 2.5 & 1.2 & 4.4 & 3.1 \\
\hline Left trade because of shoulder pain (\%) & 0.4 & 0.0 & 0.9 & 0.2 & 2.3 & 1.4 \\
\hline Current upper arm elevation above $90^{\circ} * *, \dagger † \ddagger \ddagger$ & & & & & & \\
\hline $0-3 \%$ of working hours $(\%)$ & 98.0 & 98.2 & 32.6 & 33.5 & 7.9 & 9.8 \\
\hline $3-6 \%$ of working hours $(\%)$ & 1.8 & 1.8 & 67.2 & 66.5 & 0.9 & 85.2 \\
\hline $6-9 \%$ of working hours $(\%)$ & 0.2 & 0.0 & 0.2 & 0.0 & 91.2 & 5.0 \\
\hline 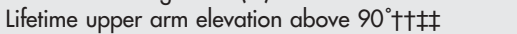 & & & & & & \\
\hline $0-6$ months (\%) & 80.8 & 59.8 & 12.6 & 10.7 & 2.0 & 8.5 \\
\hline $6-12$ months (\%) & 18.6 & 39.5 & 46.7 & 40.1 & 8.5 & 34.2 \\
\hline $12-24$ months (\%) & 0.6 & 0.8 & 40.5 & 48.6 & 40.7 & 55.4 \\
\hline$? \geqslant 24$ months $(\%)$ & 0.0 & 0.0 & 0.2 & 0.5 & 48.8 & 1.2 \\
\hline $\begin{array}{l}\text { D, dominant shoulder; ND, non-dominant shoulder. } \\
{ }^{*} \text { Calculated as number of years with regular smoking } \\
\text { to: (number of cigarettes + grams of pipe tobacco + } \\
\text { †32 missing values included. } \\
\text { †Handball, swimming, badminton, tennis, squash, fi } \\
\text { \$Diabetes, rheumatoid arthritis, psoriasis, and thyroi } \\
\text { ₹Including apprenticeship. } \\
{ }^{* *} \text { Currently employed subpopulation: } 467 \text { machinists } \\
\text { ††For definitions please refer to 'Exposure assessme } \\
\text { †¥Exposure categories include the lower limit and ex }\end{array}$ & $\begin{array}{l}\text { aily smokir } \\
\text { number of } \\
\text { training, } \\
\text { sorder. } \\
8 \text { car mech } \\
\text { text. } \\
\text { le the uppe }\end{array}$ & $\begin{array}{l}\text { ensity. } \\
\text { rs)/20. } \\
\text { liffing } \\
612 \text { t }\end{array}$ & $\begin{array}{l}\text { ntioned te } \\
\text { boxing, } \\
\text { ters. }\end{array}$ & $\begin{array}{l}\text { as expr } \\
\text { owing. }\end{array}$ & cks of & 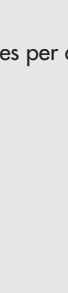 \\
\hline
\end{tabular}

A total of 732 members of the total study population were examined by SWS $(n=693)$ and JPB $(n=39)$. In order to blind the examiners to exposure status, the examinations were performed at the hospital, and the participants were instructed not to wear work clothes, to remove any stains of paint, and to put on gloves before they were seen by the examiners. The examiners were also blinded to symptoms.

The examination schedule focused on shoulder function and signs of supraspinatus pathology while ensuring that important differential diagnoses were not missed (cervical radiculopathy, instability, adhesive capsulitis). Shoulder function was assessed by Constant score. ${ }^{21}$ A maximum score ( 100 points) reflects good shoulder function according to self report ( 35 points) and objective assessment of ranges of pain free movement and shoulder strength (65 points). Strength was measured with an isometric dynamometer which provided a force average over three seconds (Isobex 2.1 by Cursor AG, Bern, Switzerland). We used the mean of five repetitions separated by five seconds. Figure 3 shows the definitions of outcome diagnoses and illustrates the relations between them.

To determine interobserver reliability, 20 subjects were specifically selected to obtain a prevalence of positive findings near $50 \%{ }^{25}$ The second examination was performed by JPB immediately after the first examination. For the abduction internal rotation test, the raw proportion of agreements between the examiners was 0.95 for both shoulders, with a $\kappa$ of 0.88 (95\% confidence interval (CI) 0.64 to 1.11 for the right shoulder and 0.67 to 1.10 for the left). For Hawkin's test, the raw proportion of agreements was 0.84 for the right shoulder and 0.95 for the left, with corresponding $\kappa$ coefficients of 0.57 (95\% CI 0.13 to 1.00$)$ and 0.90 (95\% CI 0.71 to 1.09$)$. The 
Table 2 Group means and maximum values of job exposure according to occupation and hand dominance; percentage of daily working hours with arm elevation to different extents, percentage of daily working hours with uninterrupted periods of arm elevation above $90^{\circ}$, and shoulder torque indices*

\begin{tabular}{|c|c|c|c|c|c|c|c|c|c|c|c|c|}
\hline \multirow{3}{*}{$\begin{array}{l}\text { Assessed exposures } \\
\% \text { time }>30^{\circ} \text {, mean }(\max )\end{array}$} & \multicolumn{4}{|c|}{ Machinists } & \multicolumn{4}{|c|}{ Car mechanics } & \multicolumn{4}{|c|}{ House painters } \\
\hline & \multicolumn{2}{|c|}{$\begin{array}{l}\text { Dominant } \\
n=26\end{array}$} & \multicolumn{2}{|c|}{$\begin{array}{l}\text { Non-dominant } \\
n=26\end{array}$} & \multicolumn{2}{|c|}{$\begin{array}{l}\text { Dominant } \\
n=23\end{array}$} & \multicolumn{2}{|c|}{$\begin{array}{l}\text { Non-dominant } \\
n=22\end{array}$} & \multicolumn{2}{|c|}{$\begin{array}{l}\text { Dominant } \\
n=23\end{array}$} & \multicolumn{2}{|c|}{$\begin{array}{l}\text { Non-dominant } \\
n=24\end{array}$} \\
\hline & 32.0 & (60.5) & 31.6 & (55.1) & 35.8 & $(50.6)$ & 33.8 & $(48.1)$ & 39.8 & (60.6) & 33.4 & (52.9) \\
\hline$\%$ time $>60^{\circ}$, mean $(\max )$ & 5.7 & $(20.6)$ & 7.0 & (15.0) & 10.0 & (16.7) & 11.2 & (18.9) & 16.1 & (32.8) & 11.4 & (24.5) \\
\hline$\%$ time $>90^{\circ}$, mean $(\max )$ & 1.6 & (9.0) & 2.1 & (7.5) & 4.7 & $(9.2)$ & 5.2 & (12.0) & 9.0 & (21.9) & 5.0 & (10.1) \\
\hline $\begin{array}{l}\% \text { time }>90^{\circ} \text { at least } 5 \mathrm{~s} \text {, } \\
\text { mean (max) }\end{array}$ & 0.9 & $(2.8)$ & 1.6 & $(7.0)$ & 3.4 & $(6.8)$ & 4.0 & (9.7) & 5.9 & (16.8) & 3.2 & $(7.7)$ \\
\hline $\begin{array}{l}\% \text { time }>90^{\circ} \text { at least } 10 \mathrm{~s} \text {, } \\
\text { mean }(\max )\end{array}$ & 0.7 & $(2.5)$ & 1.6 & (6.7) & 2.5 & $(4.7)$ & 3.0 & $(7.5)$ & 3.2 & (8.9) & 2.1 & (6.1) \\
\hline $\begin{array}{l}\% \text { time }>90^{\circ} \text { at least } 20 \mathrm{~s}, \\
\text { mean }(\max )\end{array}$ & 0.5 & (2.3) & 1.4 & (6.3) & 1.3 & $(2.5)$ & 1.8 & $(4.4)$ & 1.0 & (3.2) & 1.1 & (3.9) \\
\hline Torque index, mean (max) & 4.0 & $(5.9)$ & & & 7.6 & (11.5) & 7.5 & (12.4) & 4.4 & (5.9) & 4.0 & (5.7) \\
\hline
\end{tabular}

*The measurements were performed for both shoulders simultaneously. Differences in the number of dominant and non-dominant shoulders were due to technical limitations.

sensitivity of the screening questionnaire was 0.96 for dominant supraspinatus tendinitis (machinists 0.91, car mechanics 0.89 , house painters 1.00 ) and 1.00 for nondominant supraspinatus tendinitis. For shoulder pain with disability, the sensitivity was 0.95 on the dominant $(0.85$, $0.94,0.98$, respectively) and 0.88 on the non-dominant side $(0.73,0.80,0.94)$.

\section{Statistical methods}

We analysed the relation between current upper arm elevation and shoulder disorders by generalised estimating equation regression (SAS 6.12 Proc Genmod) using shoulder as the analytical unit. In side specific analyses, we related the occurrence of shoulder disorders to lifetime upper arm elevation and duration of employment by multiple logistic regression (SAS 6.12 Proc Logistic). The exposure data were analysed in categorical form, supplemented with trend analysis based on continuous variables. The odds ratios (ORs) were adjusted for fixed sets of covariates which were selected for inclusion a priori. A product term (age $[\mathrm{y}] / 10 \times$ lifetime upper arm elevation [y]) was included in analyses for interaction. The correlation between age and duration of employment was expressed as a squared Pearson correlation coefficient $\left(\mathrm{r}^{2}\right)$ (SAS 6.12 Proc Corr). We calculated 95\% Wald limits for ORs for unilateral disorders among house painters relative to the other two groups.

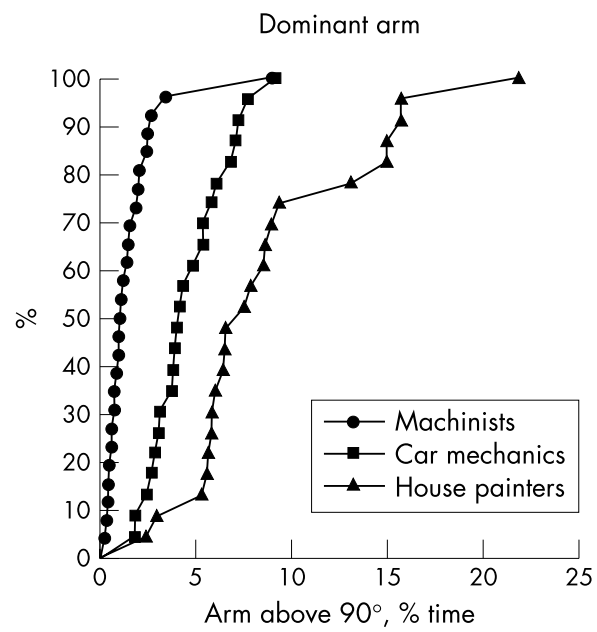

\section{RESULTS}

The prevalence of dominant sided shoulder complaints and disorders was about twice as high among house painters as in the other two groups (table 3). Exposure-response relations were found between current upper arm elevation above $90^{\circ}$ and shoulder disorders (table 4). Moreover, the prevalence of the disorders tended to increase with increasing lifetime upper arm elevation (table 5). Non-dominant supraspinatus tendinitis did not follow this general pattern, but was only represented by 18 cases. Supraspinatus tendinitis was associated with a mean Constant score of 69.8 (SD 12.4) for the dominant and 63.5 for the non-dominant shoulder.

For the dominant shoulder a 10 year increase in duration of employment in one of the three trades was associated with an OR of 0.74 (95\% CI 0.52 to 1.06) for supraspinatus tendinitis, 0.82 (95\% CI 0.65 to 1.03 ) for shoulder pain with disability, and 0.95 (95\% CI 0.77 to 1.16 ) for shoulder pain without disability (ORs adjusted for age and smoking, total study population). In analyses stratified by trade, house painters did not have higher ORs related to duration of employment than the other two groups. We found no signs of interaction between age and lifetime upper arm elevation, neither in the entire material nor in analyses stratified by trade. Age and duration of employment in one of the three trades were correlated with an $\mathrm{r}^{2}$ of 0.43 .

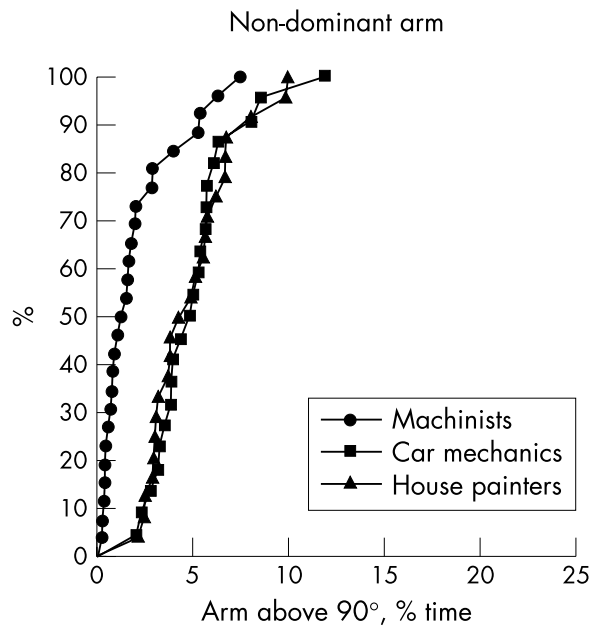

Figure 2 Individual mean percentage of daily working hours with the dominant and non-dominant arm elevated more than $90^{\circ}$. Cumulative distributions according to occupational group. Each symbol represents the arithmetic mean across four measurement days for one subject. 


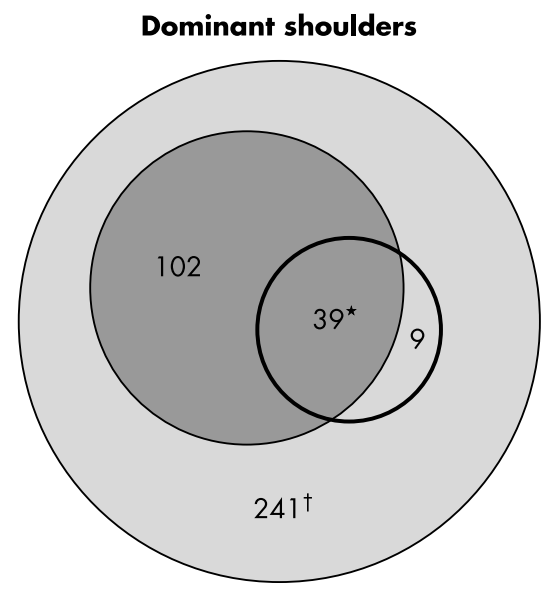

Definitions of outcome diagnoses:

\begin{tabular}{|c|c|}
\hline Shoulder pain with disability: & Constant score $\leq 80$ \\
\hline Shoulder pain without disability: & Constant score $>80$ \\
\hline O Supraspinatus tendinitis: & 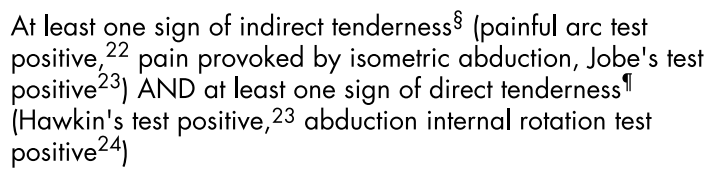 \\
\hline
\end{tabular}

Figure 3 Definitions of outcome diagnoses and relations between them for dominant and non-dominant shoulders (total study population). Screening positive shoulders (within the outer circles) received one of two complementary diagnoses - that is, shoulder pain with disability or shoulder pain without disability. Supraspinatus tendinitis was diagnosed as distinct from the classification according to disability. The number of shoulders in each category is given. *Including three shoulders with missing disability status. fIncluding 10 shoulders with missing disability status. łlncluding two shoulders with missing disability status. $\S A 10 \mathrm{~cm}$ ungraduated visual analogue scale was used to assess pain localised to the anterolateral or superior aspect of the shoulder. The scale ranged from "no pain" to "worst possible pain". Pain was recorded if the subject placed the cursor more than $3 \mathrm{~cm}$ away from the lower endpoint. "The impingement tests were positive in case of a grimace or other objective signs of pain localised to the anterolateral or superior aspect of the shoulder.

A side difference in upper arm elevation above $90^{\circ}$ was observed among house painters, but not in the other two groups (fig 2, table 2). Among house painters with unilateral supraspinatus tendinitis, the ratio between dominant and non-dominant disorders was $4.7(28 / 6)$. For the other two groups combined, the ratio was 2.3 (16/7). Thus, house painters had an excess of dominant sided supraspinatus tendinitis amounting to an OR of 2.04 (28/6:16/7) (95\% CI 0.59 to 7.13$)$ relative to the other two groups. For shoulder pain with disability, the corresponding OR was 0.71 (95\% CI 0.33 to 1.52 ), and for shoulder pain without disability 1.74 (95\% CI 1.05 to 2.99 ). In these analyses, house painters who used both hands equally well $(n=37)$ were excluded from the total study population.

Among subjects who were screening positive $(n=311$ in the currently employed subpopulation), the prevalence of shoulder symptoms which had lasted more than 90 days within the past 12 months was $47 \%, 44 \%$, and $39 \%$ in the lowest, middle, and highest category of current exposure, respectively. A similar tendency was found for the nondominant side.

\section{DISCUSSION}

Our results showed exposure-response gradients between both current and lifetime upper arm elevation above $90^{\circ}$ and shoulder disorders. Duration of employment was negatively-although not significantly-related to the outcomes. The last mentioned finding must be regarded as symptomatic of a healthy worker effect which denotes the phenomenon that individuals with health problems give up demanding trades or leave the workforce, whereas relatively healthy individuals go on working. We tried to minimise healthy worker bias by including individuals who had left their trade so that their shoulder morbidity would count in the estimated effect measures. However, the transient nature of many shoulder disorders ${ }^{26}$ may have reduced the efficiency of

Table 3 Prevalence of dominant sided shoulder complaints and disorders according to occupational group; total study population $(n=1886)$

\begin{tabular}{llll}
\hline Outcome & $\begin{array}{l}\text { Machinists } \\
\mathbf{n = 5 2 9}\end{array}$ & $\begin{array}{l}\text { Car mechanics } \\
\mathbf{n}=599\end{array}$ & $\begin{array}{l}\text { House painters } \\
\mathbf{n}=\mathbf{7 5 8}\end{array}$ \\
\hline At least moderately troubled by shoulder pain or & $15.6 \%$ & $16.8 \%$ & $31.8 \%$ \\
discomfort during the previous 12 months & $10.1 \%$ & $11.0 \%$ & $18.8 \%$ \\
Shoulder pain without disability* & $4.4 \%$ & $5.7 \%$ & $12.4 \%$ \\
Shoulder pain with disability* & $2.0 \%$ & $1.4 \%$ & $4.4 \%$ \\
Supraspinatus tendinitis & & \\
\hline *Functional measures were incomplete for 13 shoulders. & &
\end{tabular}


Table 4 Shoulder disorders in relation to current upper arm elevation above $90^{\circ}$ and other potential risk factors; currently employed subpopulation (3067 shoulders)

\begin{tabular}{|c|c|c|c|c|c|c|c|c|c|c|}
\hline \multirow{2}{*}{$\begin{array}{l}\text { Explanatory variables } \\
\text { included in the model }\end{array}$} & \multirow[b]{2}{*}{$\mathbf{n}_{\mathrm{s}}{ }^{*}$} & \multicolumn{3}{|c|}{ Supraspinatus tendinitis } & \multicolumn{3}{|c|}{ Shoulder pain with disability } & \multicolumn{3}{|c|}{ Shoulder pain without disability } \\
\hline & & $\%$ & OR & $95 \% \mathrm{Cl}$ & $\%$ & OR & $95 \% \mathrm{Cl}$ & $\%$ & OR & $95 \% \mathrm{Cl}$ \\
\hline \multicolumn{11}{|l|}{$\begin{array}{l}\text { Current upper arm elevation } \\
\text { above } 90^{\circ} \dagger\end{array}$} \\
\hline $0-3 \%$ of working hours & 1316 & 1.1 & 1.00 & - & 2.7 & 1.00 & - & 9.1 & 1.00 & - \\
\hline $3-6 \%$ of working hours & 1213 & 0.7 & 0.94 & 0.37 to 2.39 & 4.1 & 2.10 & 1.34 to 3.28 & 10.5 & 1.22 & 0.91 to 1.65 \\
\hline $6-9 \%$ of working hours & 538 & 3.9 & 4.70 & 2.07 to 10.68 & 11.0 & 3.47 & 2.02 to 5.97 & 18.3 & 1.84 & 1.30 to 2.59 \\
\hline $\begin{array}{l}\text { Trend analysis (for an } \\
\text { increment of } 1 \% \text { of } \\
\text { working hours) }\end{array}$ & 3067 & 1.4 & 1.23 & 1.10 to 1.39 & 4.7 & 1.16 & 1.08 to 1.24 & 11.3 & 1.08 & 1.04 to 1.13 \\
\hline \multicolumn{11}{|l|}{ Dominant shoulder $\ddagger$} \\
\hline No & 1551 & 0.7 & 1.00 & - & 3.0 & 1.00 & - & 8.9 & 1.00 & - \\
\hline Yes & 1516 & 2.1 & 1.39 & 0.60 to 3.22 & 6.4 & 1.85 & 1.22 to 2.83 & 13.7 & 1.38 & 1.10 to 1.73 \\
\hline \multicolumn{11}{|l|}{ Job demands } \\
\hline High & 781 & 2.6 & 3.19 & 1.62 to 6.31 & 6.2 & 1.89 & 1.25 to 2.85 & 11.9 & 1.00 & 0.73 to 1.36 \\
\hline \multicolumn{11}{|l|}{ Job control } \\
\hline High & 2027 & 1.3 & 1.00 & - & 4.4 & 1.00 & - & 11.3 & 1.00 & - \\
\hline Low & 957 & 1.6 & 1.83 & 0.93 to 3.60 & 5.0 & 1.31 & 0.87 to 1.99 & 11.3 & 1.00 & 0.75 to 1.34 \\
\hline \multicolumn{11}{|l|}{ Social support } \\
\hline High & 1893 & 1.3 & 1.00 & - & 4.1 & 1.00 & - & 10.2 & 1.00 & - \\
\hline Low & 1121 & 1.5 & 0.91 & 0.46 to 1.77 & 5.7 & 1.12 & 0.75 to 1.67 & 13.3 & 1.28 & 0.97 to 1.68 \\
\hline \multicolumn{11}{|l|}{ Age $(y) \dagger$} \\
\hline $30-40$ & 1068 & 0.8 & 1.00 & - & 2.2 & 1.00 & - & 10.3 & 1.00 & - \\
\hline $40-50$ & 919 & 1.1 & 1.37 & 0.54 to 3.44 & 3.2 & 1.37 & 0.74 to 2.53 & 13.7 & 1.26 & 0.91 to 1.73 \\
\hline $50-60$ & 963 & 2.1 & 2.32 & 0.99 to 5.40 & 8.6 & 3.78 & 2.24 to 6.39 & 10.5 & 0.88 & 0.62 to 1.25 \\
\hline $60-70$ & 117 & 3.4 & 3.92 & 1.05 to 5.42 & 7.7 & 3.86 & 1.62 to 9.20 & 6.8 & 0.62 & 0.28 to 1.37 \\
\hline \multicolumn{11}{|l|}{ Smoking (pack-years) $\dagger$} \\
\hline 0 & 1114 & 1.2 & 1.00 & - & 2.6 & 1.00 & - & 9.9 & 1.00 & - \\
\hline $0-20$ & 1153 & 1.3 & 0.74 & 0.33 to 1.67 & 5.4 & 1.91 & 1.13 to 3.21 & 11.3 & 1.12 & 0.82 to 1.54 \\
\hline$\geqslant 20$ & 800 & 1.9 & 0.99 & 0.45 to 2.18 & 6.7 & 1.76 & 1.02 to 3.02 & 13.1 & 1.35 & 0.96 to 1.90 \\
\hline
\end{tabular}

$\mathrm{n}_{\mathrm{s}}$, number of shoulders, \%, percentage of shoulders with disorder; OR, odds ratio; $\mathrm{Cl}$, confidence interval.

*The totals may differ from the total number of shoulders due to missing values.

tCategories include the lower limit and exclude the upper limit.

$\ddagger$ Subjects were classified as right handed if they used both hands equally well.

Table 5 Shoulder disorders in relation to lifetime upper arm elevation above $90^{\circ}$; total study population $(n=1886)$

\begin{tabular}{|c|c|c|c|c|c|c|c|c|c|c|c|c|c|}
\hline \multirow{2}{*}{$\begin{array}{l}\text { Lifetime } \\
\text { exposure } \\
\text { (mth) }\end{array}$} & \multicolumn{6}{|c|}{ Dominant shoulder } & \multirow{2}{*}{$\begin{array}{l}\text { Lifetime } \\
\text { exposure } \\
\text { (mth) }\end{array}$} & \multicolumn{6}{|c|}{ Non-dominant shoulder } \\
\hline & n & c & $\%$ & $\mathrm{OR}_{\text {crude }}$ & $\mathrm{OR}_{\mathrm{adi}}$ & $95 \% \mathrm{Cl}$ & & $\mathbf{n}$ & c & $\%$ & $\mathrm{OR}_{\text {crude }}$ & $\mathrm{OR}_{\mathrm{adi}}$ & $95 \% \mathrm{Cl}$ \\
\hline \multicolumn{14}{|c|}{ Supraspinatus tendinitis } \\
\hline $0-6$ & 491 & 10 & 2.0 & 1.00 & 1.00 & - & $0-6$ & 429 & 3 & 0.7 & 1.00 & 1.00 & - \\
\hline $6-12$ & 427 & 7 & 1.6 & 0.80 & 0.73 & 0.27 to 1.94 & $6-12$ & 682 & 8 & 1.2 & 1.69 & 0.97 & 0.25 to 3.85 \\
\hline $12-24$ & 519 & 14 & 2.7 & 1.33 & 1.30 & 0.57 to 2.99 & $\geqslant 12$ & 686 & 7 & 1.0 & 1.46 & 0.54 & 0.13 to 2.24 \\
\hline$\geqslant 24$ & 315 & 17 & 5.4 & 2.74 & 1.87 & 0.79 to 4.44 & & & & & & & \\
\hline \multicolumn{7}{|c|}{$\begin{array}{l}\text { Trend analysis (for an increment of } 6 \text { months): } \\
\text { OR adi } 1.14(95 \% \mathrm{Cl} 0.97 \text { to } 1.35)\end{array}$} & \multicolumn{7}{|c|}{$\begin{array}{l}\text { Trend analysis (for an increment of } 6 \text { months): } \\
\text { OR adi } 0.64 \text { (95\% } \mathrm{Cl} 0.39 \text { to } 1.08)\end{array}$} \\
\hline \multicolumn{14}{|c|}{ Shoulder pain with disability } \\
\hline $0-6$ & 486 & 23 & 4.7 & 1.00 & 1.00 & - & $0-6$ & 428 & 7 & 1.6 & 1.00 & 1.00 & - \\
\hline $6-12$ & 423 & 21 & 5.0 & 1.05 & 1.04 & 0.56 to 1.93 & $6-12$ & 682 & 23 & 3.4 & 2.10 & 1.43 & 0.59 to 3.43 \\
\hline $12-24$ & 517 & 45 & 8.7 & 1.92 & 1.75 & 1.03 to 2.97 & $\geqslant 12$ & 685 & 44 & 6.4 & 4.13 & 1.93 & 0.81 to 4.57 \\
\hline$\geqslant 24$ & 313 & 49 & 15.7 & 3.74 & 2.23 & 1.28 to 3.88 & & & & & & & \\
\hline \multicolumn{7}{|c|}{$\begin{array}{l}\text { Trend analysis (for an increment of } 6 \text { months): } \\
\mathrm{OR}_{\text {adi }} 1.18(95 \% \mathrm{Cl} 1.06 \text { to } 1.30)\end{array}$} & \multicolumn{7}{|c|}{$\begin{array}{l}\text { Trend analysis (for an increment of } 6 \text { months): } \\
\left.\text { OR }_{\text {adj }} 1.26 \text { ( } 95 \% \mathrm{Cl} 0.97 \text { to } 1.64\right)\end{array}$} \\
\hline \multicolumn{14}{|c|}{ Shoulder pain without disability } \\
\hline $0-6$ & 486 & 54 & 11.1 & 1.00 & 1.00 & - & $0-6$ & 428 & 34 & 8.0 & 1.00 & 1.00 & - \\
\hline $6-12$ & 423 & 50 & 11.8 & 1.07 & 1.11 & 0.74 to 1.70 & $6-12$ & 682 & 59 & 8.3 & 1.10 & 1.10 & 0.71 to 1.71 \\
\hline $12-24$ & 517 & 88 & 17.0 & 1.64 & 1.68 & 1.16 to 2.44 & $\geqslant 12$ & 685 & 67 & 9.8 & 1.26 & 1.39 & 0.82 to 1.93 \\
\hline$\geqslant 24$ & 313 & 48 & 15.3 & 1.45 & 1.85 & 1.16 to 2.94 & & & & & & & \\
\hline \multicolumn{7}{|c|}{$\begin{array}{l}\text { Trend analysis (for an increment of } 6 \text { months): } \\
\text { OR }_{\text {adj }} 1.16(95 \% \mathrm{Cl} 1.06 \text { to } 1.27)\end{array}$} & \multicolumn{7}{|c|}{$\begin{array}{l}\text { Trend analysis (for an increment of } 6 \text { months): } \\
\left.\mathrm{OR}_{\mathrm{adj}} 1.19 \text { ( } 95 \% \mathrm{Cl} 0.97 \text { to } 1.46\right)\end{array}$} \\
\hline \multicolumn{14}{|c|}{$\begin{array}{l}\text { n, number of subjects; c, number of cases; \%, prevalence, } O R_{\text {crude, }} \text { unadjusted odds ratio; } O R_{\text {adi, }} \text { adjusted odds ratio (adjusted for } 10 \text { year age categories ( } 30-40 \text {, } \\
40-50,50-60,60-70) \text { and categorised pack-years of smoking }(0,0-20,20) \text {; age and smoking categories include the lower limit and exclude the upper limit). } \\
\text { Subjects were classified as right handed if they used both hands equally well. } \\
\text { In analyses for the non-dominant shoulder, } 14 \text { subjects with lifetime upper arm elevation } \geqslant 24 \text { months were included in the category } \geqslant 12 \text { months. Two of these } \\
\text { subjects had shoulder pain with disability, none of them had shoulder tendinitis or shoulder pain without disability } \\
\text { Exposure categories include the lower limit and exclude the upper limit. }\end{array}$} \\
\hline
\end{tabular}


this approach to the extent that shoulder disorders among individuals who had left their trade did not persist until the time of the study.

The diagnosis supraspinatus tendinitis required a positive impingement test. For impingement syndrome defined as a positive abduction internal rotation test combined with shoulder symptoms that had lasted at least three months within the past year, a prevalence of $6.9 \%$ was found among current slaughterhouse workers compared to $1.3 \%$ among employees at a chemical factory. ${ }^{27}$ The prevalence proportions in the present study ranged between these extremes (table 3 ). In the Danish Project on Research and Intervention in Monotonous Work, supraspinatus tendinitis was defined in terms of symptoms in combination with pain at resisted abduction and palpation tenderness of the greater humeral tubercle and/or impingement pain. ${ }^{28}{ }^{29}$ Thus defined, the overall prevalence of supraspinatus tendinitis was $3.2 \%,{ }^{28}$ ranging from $0 \%$ in shops and post sorting centres ${ }^{28}$ to $5.8 \%$ among female sewing machine operators ${ }^{29}$ and $8.7 \%$ among slaughterhouse workers. ${ }^{28}$ Relaxing the criteria to shoulder pain combined with local tenderness over the tendon insertion and pain at resisted isometric abduction, ${ }^{30}$ a prevalence of $15 \%$ was found among women in the fish processing industry. ${ }^{31}$ Applying the same criteria, $10 \%$ and $12 \%$ of women with repetitive industrial work had supraspinatus tendinitis versus $0 \%$ and $2 \%$ in control groups with more varied work. ${ }^{32}{ }^{33}$ A study of construction workers did not require an experience of shoulder pain, only pronounced pain elicited by palpation of the muscle attachments or pronounced pain reaction to isometric contraction of the rotator cuff or biceps muscles. ${ }^{34}$ For the dominant shoulder, the prevalence of such signs of tendinitis was $40 \%$ among rock blasters versus about $15 \%$ among bricklayers and foremen. $^{34}$ It appears that the prevalence of shoulder tendinitis in the referent groups was similar across studies, ${ }^{27-33}$ except when the most lenient diagnostic criteria were applied. ${ }^{34}$ The large differences observed, for example, between slaughterhouse workers and bricklayers, probably reflected differences in case definitions (and presumably, gender differences contributed to the overall variability). Our definition of shoulder tendinitis was strict and the cases seemed to be comparable to cases identified among slaughterhouse and chemical factory workers where a positive impingement test was associated with a mean Constant score of 64 points (SD 18). ${ }^{27}$ Thus, the prevalence of supraspinatus tendinitis was clearly increased among house painters when compared to different reference groups, but did not reach the level observed among slaughterhouse workers.

Highly elevated arm postures occurred to some extent among machinists who constituted the reference group in the present study. Consequently, the prevalence of shoulder complaints among machinists may not have represented the experience of an "unexposed" population. This may have lead to underestimated effect measures.

If house painters with shoulder complaints were more likely to participate than machinists and car mechanics with similar symptoms, the results would be biased. According to telephone interviews with about one third $(n=278)$ of the questionnaire non-respondents, $24 \%, 8 \%$, and $22 \%$ of the dominant shoulders were screening positive among machinists, car mechanics, and house painters, respectively. Thus, shoulder symptoms appeared to be over-represented by participating house painters (ratio 1.5) and under-represented by participating machinists (ratio 0.7) (cf table 3) with an ensuing tendency for overestimating the true relation between work with elevated arms and shoulder disorders. However, the over-representation was even more pronounced among car mechanics (ratio 2.3) than among house painters, and the proportion responding to the questionnaire was satisfactory in all three groups. Moreover, there was only a small drop out of screening positive subjects before the physical examinations. Thus, apart from the healthy worker effect, we do not consider selection bias a problem in this study.

The cross sectional study design implied a risk of length bias due to over-representation of cases with long duration. ${ }^{35}$ Therefore, the observed exposure-response relations might merely reflect a prognostic relation. However, the duration of shoulder symptoms decreased with increase of current upper arm elevation which means that our results reflected an increased risk of developing shoulder disorders. Due to the possibility of healthy worker bias, our findings do not preclude that work with elevated arms may be a prognostic determinant as well.

Pain on elevation of the arm is a common symptom of various shoulder disorders and, consequently, work above shoulder level may provoke pain even if the exposure is neither causally nor prognostically related to any underlying disorder. Therefore, the use of questionnaire data to select individuals for physical examination implied a risk of detection bias. However, the sensitivity of the screening questionnaire was high which reduced this possibility. Detection bias was also minimised by means of objective outcome measures. The examiners were effectively blinded to exposure status so this source of information bias was ruled out.

To counteract confounding, we restricted the study to men from trades with the same socioeconomic status as a proxy of health related behaviour. We controlled for several possible confounders in the analyses, and by including both shoulders in correlated logistic regression analyses, we adjusted for extraneous factors which affected both shoulders equally. For house painters, the exposure difference between the dominant and non-dominant shoulder appeared to be the most obvious explanation of the occurrence of dominant sided shoulder disorders in excess of the side difference observed in the other two groups. House painters did not have a relative excess of dominant sided shoulder pain with disability which may be explained by feedback bias because house painters were able to change their work practices in case of shoulder problems. Relatively more house painters stated that they had changed work practices permanently due to shoulder pain (table 1).

The Karasek-Theorell three factor model of psychological demand, control, and support ${ }^{36}$ has had great impact on epidemiological research into the relation between psychosocial working conditions and musculoskeletal pain syndromes. Inconsistent results have been obtained on associations between these factors and self reported shoulder pain, but the evidence seems to suggest a relation. ${ }^{6738} \mathrm{~A}$ recent extensive review of the literature ${ }^{38}$ included only three studies on a possible association with clinically verified shoulder disorders, and the results were difficult to compare. We included demand-control-support variables in the analyses, and high job demands were significantly associated with shoulder tendinitis and shoulder pain with disability, but not with shoulder pain without disability (table 4). One explanation of this may be that high perceived job demands are associated with increased mechanical exposure levels. ${ }^{38}$ Several other psychosocial factors have been related to painful shoulder syndromes, the most prominent being high perceived job stress. ${ }^{38}$ At present, however, the conceptual distinction between perceived job demands and perceived job stress seems unclear as does the possible correlation between psychosocial and mechanical exposures.

The three occupational groups were selected to minimise repetitive work, and long periods of sustained arm elevation occurred very rarely (table 2). High force requirements 
combined with upper arm elevation did not explain the increased occurrence of shoulder disorders among house painters, because on average car mechanics had the highest torque index (table 2). Furthermore, the associations could not be explained by the extent of upper arm elevation above $30^{\circ}$, since the exposure contrast between occupations was negligible for this variable (table 2). The percentages of daily working hours with the arm elevated above $60^{\circ}$ and above $90^{\circ}$ were strongly correlated at the group level (table 2 ). Therefore it was not possible to discern the effects of these two levels of arm elevation. Nevertheless, the results provided evidence of a relation between shoulder disorders and highly elevated arm postures during work.

The exposure assessment strategy implied misclassification of individual exposures because the group means were assigned to all subjects belonging to an occupational group, even though they varied in exposure (table 2, fig 2). Most often random error in exposure measures leads to a tendency for underestimation of true associations, a phenomenon which is known as attenuation. ${ }^{39} 40$ Based on the exposure variability in the exposure survey (cf table 2 ), we estimated that when corrected for the attenuating effect of exposure variability, the observed ORs of 4.70, 3.47, and 1.84 for the highest level of current exposure ( $\mathrm{cf}$ table 3 ) corresponded to corrected ORs of about 6.0, 4.0, and 1.9, respectively. ${ }^{40}$

The fact that duration of employment in one of the three trades was unrelated to the outcomes suggested that the observed relations with lifetime upper arm elevation should not be interpreted as evidence of cumulative effects. The associations more likely reflected the importance of exposure intensity. Long term age independent accumulation was not shown. Thus, our findings were compatible with a relatively short induction period for shoulder pain as suggested in a recent study. ${ }^{41}$ Moreover, our results are not necessarily in conflict with previous studies stating that duration of employment is a risk factor ${ }^{7}$ because duration of employment must be interpreted as a surrogate for cumulative effects of all generic exposures received. We are not aware of previous studies of measured upper arm elevation above $90^{\circ}$ and clinically verified shoulder disorders, but the relations found in this study seemed to agree with observations in a recent study of automobile assembly workers. ${ }^{12}$

In conclusion, quantitative exposure-response relations were established between current work with highly elevated arms and clinically verified shoulder disorders. Substantial long term cumulative effects were not shown. Due to possible sources of bias and measurement error, the observed ORs may underestimate the true associations. The investigation revealed a potential for primary prevention of shoulder disorders by redesigning jobs so that work with highly elevated arms is minimised.

\section{ACKNOWLEDGEMENTS}

The project was funded by the Danish National Working Environment Authority (grant no. 20000008674/16), the Danish Rheumatism Association (grant nos 233-1021-21.07.98 and 2331021-23.9.99), the Danish Health Insurance Fund (grant no. 11/27198), and the Research Initiative of Aarhus University Hospital (grant no. 2-16-4-12-98). SW Svendsen was supported by the Faculty of Health Sciences, University of Aarhus, Denmark. SE Mathiassen did part of his work while being a visiting scholar at the Liberty Mutual Research Institute for Safety in Hopkinton, MA, USA.

\section{Authors' affiliations}

S W Svendsen, J P Bonde, Department of Occupational Medicine, Aarhus University Hospital, Denmark

S E Mathiassen, Department of Occupational and Environmental Medicine, Lund University Hospital, Sweden

K Stengaard-Pedersen, Department of Rheumatology, Aarhus University Hospital, Denmark
L H Frich, Department of Orthopaedic Surgery, Odense University Hospital, Denmark

\section{REFERENCES}

1 Nygren A, Berglund A, von Koch M. Neck-and-shoulder pain, an increasing problem. Strategies for using insurance material to follow trends. Scand J Rehabil Med Suppl 1995;32:107-12.

2 van der Windt DAWM, Koes BW, de Jong BA, et al. Shoulder disorders in general practice: incidence, patient characteristics, and management. Ann Rheum Dis 1995;54:959-64

3 Vecchio P, Kavanagh R, Hazleman BL, et al. Shoulder pain in a communitybased rheumatology clinic. Br J Rheumatol 1995;34:440-2.

4 Vitale MG, Krant JJ, Gelijns AC, et al. Geographic variations in the rates of operative procedures involving the shoulder, including total shoulder replacement, humeral head replacement, and rotator cuff repair. J Bone Joint Surg Am 1999;81:763-72.

5 Lund T. Associations between health and work disability [thesis]. Copenhagen: National Institute of Occupational Health and Department of Epidemiology and Surveillance, 2001.

6 Bernard BP. Musculoskeletal disorders and workplace factors: a critical review of epidemiologic evidence for work-related musculoskeletal disorders of the neck, upper extremity, and low back. Cincinnati, $\mathrm{OH}$ : National Institute for Occupational Safety and Health (NIOSH), 1997.

7 van der Windt DA, Thomas E, Pope DP, et al. Occupational risk factors for shoulder pain: a systematic review. Occup Environ Med 2000;57:433-42.

8 Riihimäki H. Musculoskeletal diseases - a continuing challenge for epidemiologic research. Scand J Work Environ Health 1999;25(suppl 4):31-5.

9 Kilbom A. Possibilities for regulatory actions in the prevention of musculoskeletal disorders. Scand J Work Environ Health 1999;25(suppl 4):5-12.

10 Armstrong TJ, Buckle P, Fine $\sqcup$, et al. A conceptual model for work-related neck and upper-limb musculoskeletal disorders. Scand J Work Environ Health 1993; 19:73-84.

11 Bjelle A, Hagberg M, Michaelsson G. Clinical and ergonomic factors in prolonged shoulder pain among industrial workers. Scand J Work Environ Health 1979;5:205-10.

12 Punnett L, Fine $\amalg$, Keyserling WM, et al. Shoulder disorders and postural stress in automobile assembly work. Scand J Work Environ Health 2000;26:283-91

13 Sakakibara H, Miyao M, Kondo T, et al. Overhead work and shoulder-neck pain in orchard farmers harvesting pears and apples. Ergonomics 1995;38:700-6.

14 Herberts $P$, Kadefors R, Högfors $C$, et al. Shoulder pain and heavy manual labor. Clin Orthop 1984;191:166-78.

15 Holmström EB, Lindell J, Moritz U. Low back and neck/shoulder pain in construction workers: occupational workload and psychosocial risk factors. Part 2: relationship to neck and shoulder pain. Spine 1992;17:672-7.

16 Holmström E, Engholm G. Musculoskeletal disorders in relation to age and occupation in Swedish construction workers. Am J Ind Med 2003:44:377-84.

16a Svendsen SW, Bone JP, Mathiassen SE. Task-based exposure assessment in ergonomic epidemiology: a study of upper arm elevation in the jobs of machinists, car mechanics, and house painters. Occup Environ Med. Submitted.

17 Mortimer M, Wigaeus-Hjelm E, Wiktorin C, et al. Validity of self-reported duration of work postures obtained by interview. Appl Ergon 1999;30:477-86

18 Mathiassen SE, Winkel J. Quantifying variation in physical load using exposure-vs-time data. Ergonomics 1991;34:1455-68.

19 Kristensen TS, Borg V, Hannerz H. Socioeconomic status and psychosocial work environment: results from a Danish national study. Scand J Public Health 2002; (suppl 59):41-8.

20 Kuorinka I, Jonsson B, Kilbom A, et al. Standardised Nordic questionnaires for the analysis of musculoskeletal symptoms. Appl Ergon 1987;18:233-7.

21 Constant CR, Murley AH. A clinical method of functional assessment of the shoulder. Clin Orthop 1987;214:160-4.

22 Çaliș M, Akgün K, Birtane M, et al. Diagnostic values of clinical diagnostic tests in subacromial impingement syndrome. Ann Rheum Dis 2000;59:44-7

23 Tennent TD, Beach WR, Meyers JF. A review of the special tests associated with shoulder examination. Part I: the rotator cuff tests. Am J Sports Med 2003;31:154-60.

24 lannotti JP. Evaluation of the painful shoulder. J Hand Ther 1994;7:77-83.

25 Hoehler FK. Bias and prevalence effects on kappa viewed in terms of sensitivity and specificity. J Clin Epidemiol 2000;53:499-503.

26 Bonde JP, Mikkelsen S, Andersen JH, et al. Prognosis of shoulder tendonitis in repetitive work: a follow up study in a cohort of Danish industrial and service workers. Occup Environ Med 2003;60:E8.

27 Frost $\mathrm{P}$, Andersen JH. Shoulder impingement syndrome in relation to shoulder intensive work. Occup Environ Med 1999;56:494-8.

28 Frost $\mathbf{P}$, Bonde JP, Mikkelsen S, et al. Risk of shoulder tendinitis in relation to shoulder loads in monotonous repetitive work. Am J Ind Med 2002;41:1 1-18.

29 Kærgaard A, Andersen JH. Musculoskeletal disorders of the neck and shoulders in female sewing machine operators: prevalence, incidence, and prognosis. Occup Environ Med 2000;57:528-34.

30 Ohlsson K, Attewell RG, Johnsson B, et al. An assessment of neck and upper extremity disorders by questionnaire and clinical examination. Ergonomics 1994;37:891-7. 
31 Ohlsson K, Hansson G-Å, Balogh I, et al. Disorders of the neck and upper limbs in women in the fish processing industry. Occup Environ Med 1994;51:826-32.

32 Hansson G-Å, Balogh I, Ohlsson K, et al. Impact of physical exposure on neck and upper limb disorders in female workers. Appl Ergon 2000;31:301-10.

33 Ohlsson K, Attewell RG, Pålsson B, et al. Repetitive industrial work and neck and upper limb disorders in females. Am J Ind Med 1995;27:731-47.

34 Stenlund B, Goldie I, Hagberg M, et al. Shoulder tendinitis and its relation to heavy manual work and exposure to vibration. Scand J Work Environ Health 1993; 19:43-9.

35 Rothman KJ, Greenland S. Types of epidemiologic studies. In: Rothman KJ, Greenland S, eds. Modern epidemiology, 2nd edn. Philadelphia: LippincottRaven Publishers, 1998:67-78.

36 Karasek R, Theorell T. Healthy work: stress, productivity, and the reconstruction of working life. New York: Basic Books, 1990.
37 Bongers PM, de Winter CR, Kompier MA, et al. Psychosocial factors at work and musculoskeletal disease. Scand J Work Environ Health 1993;19:297-312.

38 Bongers PM, Kremer AM, ter Laak J. Are psychosocial factors, risk factors for symptoms and signs of the shoulder, elbow, or hand/wrist? A review of the epidemiological literature. Am J Ind Med 2002;41:315-42.

39 Armstrong BG. Effect of measurement error on epidemiological studies of environmental and occupational exposures. Occup Environ Med 1998:55:651-6.

40 Reeves GK, Cox DR, Darby SC, et al. Some aspects of measurement error in explanatory variables for continuous and binary regression models. Stat Med 1998; 17:2157-77.

41 Fredriksson K, Alfredsson L, Ahlberg G, et al. Work environment and neck and shoulder pain: the influence of exposure time. Results from a population based case-control study. Occup Environ Med 2002;59:182-8.

\section{$\mathrm{ECHO}$}

\section{TIMP-3 promoter variants and pigeon breeder's disease}

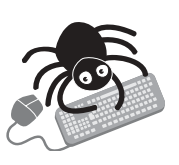

Please visit the Occupational and

Environmental Medicine website [www. occenvmed. com] for a link to the full text of this article.
$P$ igeon breeder's disease (PBD) is a granulomatous inflammatory disease of the lung that occurs in people exposed to bird antigens (hypersensitivity pneumonitis). In this and several other diseases, such as idiopathic pulmonary fibrosis (IPF), rheumatoid arthritis, and cancer, there is a change in the balance of proteolysis and antiproteolysis brought about by matrix metalloproteinases (MMPs) and the tissue inhibitors of metalloproteinases (TIMPs). This balance determines the turnover of extracellular matrix. There is evidence that polymorphisms in MMP and TIMP genes may influence susceptibility to disease. Researchers in Mexico and the UK have assessed the role of promoter variants in the TIMP-3 gene because of TIMPs $-1,-2,-3$, and -4 , only TIMP-3 binds strongly to extracellular matrix.

They studied the allele frequency and genotype distribution of two TIMP-3 promoter polymorphisms, $-915 \mathrm{~A}>\mathrm{G}$ and $-1296 \mathrm{~T}>\mathrm{C}$, among 622 Mexican adults, 115 with PBD, 90 bird keepers without PBD, 94 with IPF, and 323 healthy controls. Each of the variants occurred in about one in $300(0.33 \%)$ in each of the control and IPF groups and about one in $444(0.225 \%)$ of the PBD group. Carriage of at least one variant allele was $52 \%$ protective against PBD. Of four haplotypes at positions -915 and -1296 the ${ }^{*} \mathrm{G}^{*} \mathrm{C}$ haplotype was $47 \%$ protective against PBD. Among subjects in the $\mathrm{PBD}$ group the ${ }^{*} \mathrm{G}^{*} \mathrm{C}$ haplotype did not influence lung function or severity of lung fibrosis but this haplotype was associated with a reduction in the proportion of cells in bronchoalveolar lavage fluid that were lymphocytes.

The two promoter variants in the TIMP-3 gene were associated with reduced risk of PBD possibly because of reduced inflammatory reaction rather than a reduction in fibrosis.

A Hill M R, et al. Thorax 2004;59:586-590. 